\title{
Important progress towards elimination of onchocerciasis in the West Region of Cameroon
}

Guy-Roger Kamga ${ }^{1,2,3^{*}}$, Fanny N. Dissak-Delon ${ }^{1,2,4}$, Hugues C. Nana-Djeunga ${ }^{2,5}$, Benjamin D. Biholong ${ }^{1}$, Stephen Mbigha Ghogomu ${ }^{6}$, Jacob Souopgui ${ }^{4}$, Joseph Kamgno ${ }^{2,5}$ and Annie Robert ${ }^{3}$

\begin{abstract}
Background: After more than a decade of community-directed treatment with ivermectin (CDTI) in the West Region of Cameroon, epidemiological evaluation conducted in 2011 showed that onchocerciasis endemicity was still high in some communities. The conceptual framework for onchocerciasis elimination recommends in such case, to conduct additional phase 1A surveys at intervals of three to four years. Therefore, to assess the progress made towards the elimination of onchocerciasis in the West CDTI projects, we conducted a cross-sectional survey in May 2015 in 15 unevaluated communities where the highest baseline endemicity level were found in 1996. All volunteers living for at least five years in the community, aged five years or more, underwent clinical and parasitological examinations. Individual adherence to ivermectin treatment was also assessed. Analyses of data were weighted proportionally to age and gender distribution in the population.
\end{abstract}

Results: The mean age was $28.4 \pm 22.2$ years and there were $55 \%$ of women among the 2058 individuals examined. The weighted prevalences were $5.5 \%, 2.1 \%$ and $1.7 \%$ for microfilaridermia, nodule and cutaneous signs, respectively. The weighted microfilaridermia prevalences varied from 4.0 in 5-9 years old to $11.6 \%$ in $40-49$ years old. In the 30 children under 10 years examined in Makouopsap, the weighted prevalences were $49.9 \%$ for microfilaridermia and $13.3 \%$ for nodule. In surveyed communities, the weighted prevalences varied from 0 to $41.6 \%$ for microfilaridermia, with 11 (73.3\%) communities having <5\%. Except Makouopsap which had 41.6\%, all the surveyed communities were below 15\% for microfilaridermia prevalence. The community microfilarial load (CMFL) expressed in microfilariae/skin snip (mf/ss), also significantly dropped by 98-100\%, from 3.75-33.16 mf/ss in 1996 to $0-0.94 \mathrm{mf} / \mathrm{ss}$ in 2015 . The weighted therapeutic coverage in 2014 was $69.4 \%$ and the 5 years' adherence was only 39.3\% among participants.

Conclusions: After more than 15 years of CDTI, there is an important progress towards the elimination of onchocerciasis in the communities surveyed. Innovative strategy like semi-annual ivermectin treatment plus vector control or the adjunction of a vector control strategy to the current annual treatment should be implemented in the bordering districts of the Centre and West Regions, as well as in other parts of the country with persistent high prevalences in the sight of onchocerciasis elimination.

Keywords: Onchocerciasis, Ivermectin, Persistence, Elimination, West Region, Cameroon

\footnotetext{
* Correspondence: guyrogerkgr@gmail.com

'Ministry of Public Health, №8, Rue 3038 quartier du Lac, Yaoundé,

Cameroon

${ }^{2}$ Centre for Research on Filariasis and other Tropical Diseases (CRFilMT), P.O.

Box 5797, Yaoundé, Cameroon

Full list of author information is available at the end of the article
} 


\section{Background}

Onchocerciasis, better known as river blindness, is a debilitating insect-borne parasitic disease caused by Onchocerca volvulus and transmitted via the bites of blackflies of the genus Simulium. The larvae and pupae of the latter develop in fast-flowing and well-oxygenated streams and rivers. The prevalence of infection and disease in a community is therefore related to riverine breeding sites of the vector. The disease is endemic in 31 African countries, in Yemen and in two localized foci of two Latin American countries (Brazil and Venezuela). It was eliminated in Columbia (2013), Ecuador (2014), Mexico (2015) and Guatemala (2016) [1]. Among the estimated 187 million people living in areas where there is a potential for transmission of the parasite worldwide in 2015, 99\% of them live in Africa. It is estimated that 37 million people were infected in 1995, when the African Programme for Onchocerciasis Control (APOC) was launched [2, 3].

The adult $O$. volvulus has an estimated average lifespan of 10 years with some worms thought to live as long as 15 years $[4,5]$. The female adult worm produces thousands of microfilariae daily which invade the host dermis and eyes. The various skin symptoms (severe skin damage with unrelenting itches) and ocular symptoms (visual impairment and blindness) of onchocerciasis [6-8] are induced by the inflammatory responses to the dead of microfilariae [9]. After trachoma, irreversible onchocercal blindness is ranked as the world's second leading infectious cause of preventable blindness [10]. Onchocerciasis is a neglected tropical disease (NTD), that creates stigma, generates and perpetuates poverty, and is an impediment to socioeconomic development.

Ivermectin is currently the only known effective and safe drug used for mass treatments against onchocerciasis. However, it has a limited macrofilaricidal activity, thus treatments must be repeated for at least 12-15 years, corresponding to the reproductive lifespan of the adult worm when exposed to drug pressure. The control of onchocerciasis has been quite successful with the implementation of Community Directed Treatment with Ivermectin (CDTI). This strategy, proposed by the World Health Organization (WHO) through APOC, has significantly improved ivermectin treatment coverage [11-13]. While this drug has been administrated twice or four times a year in the small and well-delineated endemic communities of the Americas, only single doses have been given yearly in the much larger foci of African endemic countries $[14,15]$. As a consequence, the programmes in the Americas are highly successful and the disease has been eliminated in four Latin America countries [16-19], while it remains a public health problem in Africa. Nevertheless, new evidence points exist towards the possibility of successful elimination of river blindness in Africa using ivermectin solely $[20,21]$. Indeed, a spectacular decrease in microfilaridermia prevalence below $1 \%$ was reported in Mali, Senegal and Uganda [21, 22], as well as in some CDTI-projects in the APOC countries [1, 23, 24]. However, despite more than 20 years of disease control, onchocerciasis remains a major concern in some foci of several endemic countries, including Cameroon [24, 25].

The phase 1 of the APOC's conceptual framework for onchocerciasis elimination [26] has two sequential objectives: (i) to evaluate the progress towards elimination by assessing the decline in infection levels in the human population towards provisional thresholds for elimination (evaluation phase 1A), and (ii) to confirm, using both parasitological and entomological indicators, that the provisional threshold has been reached and that the treatment can be safely stopped (evaluation phase $1 \mathrm{~B}$ and the end of phase 1).

Indeed, recent phase 1A surveys conducted in 2011 by WHO/APOC revealed onchocerciasis prevalences above $60 \%$ in some foci of the Centre 1, Littoral 2 and West CDTI-projects in Cameroon [24]. The reasons for such persistence of the infection are to be elucidated yet, and it is not clear whether this is due to low treatment coverage, systematic non-adherence of a proportion of the population, or suboptimal response of the parasite to ivermectin. These poor results led to the implementation of some corrective measures (frequent and regular supportive supervision, data quality audit, community self-monitoring and a better drug management) by the National Onchocerciasis Control Programme (NOCP) to improve the CDTI performances. In such case where the prevalence remains high, additional phase $1 \mathrm{~A}$ surveys would be needed at intervals of three to four years.

The objective of the present survey was therefore, to assess the progress made towards the elimination of onchocerciasis in the West CDTI project by assessing unevaluated communities where the highest endemicity levels were found in 1996, before the launch of control measures. This assessment was based on previous APOC's conceptual framework for onchocerciasis elimination as it was conducted before the publication of the new 2016 WHO revised guidelines on stopping mass drug administration (MDA) and verifying elimination which advocate xenomonitoring and serology [27].

\section{Methods \\ Study area}

The present study was conducted in seven health districts (HD) out of the 20 of the West Region. The West Region $\left(5^{\circ} 30^{\prime} 0^{\prime \prime} \mathrm{N}, 10^{\circ} 30^{\prime} 0^{\prime \prime} \mathrm{E}\right)$ is $13,892 \mathrm{~km}^{2}$ of territory located in the central-western portion of the Republic of Cameroon. It borders the Northwest Region to the northwest, the Adamawa Region to the northeast, the Centre Region to the southeast, the Littoral Region to 
the southwest, and the Southwest Region to the west (Fig. 1). The West Region is the smallest of Cameroon's ten regions in area. However, with its population estimated at 1,895,102 inhabitants in 2014 based on a census conducted by community directed distributors (CDD), it has the highest population density (136.4 inhabitants $/ \mathrm{km}^{2}$ ). Its relief is mountainous with altitude varying from as low as $500 \mathrm{~m}$ in the Noun and Nkam valleys to $1000-2500 \mathrm{~m}$ in Western High Plateau. It is a forest-savanna transition zone, irrigated by many fastflowing rivers including the tributaries of the Sanaga in the east (Métchié, Mifi, Nkoup, Ndé, Noun) and the tributaries of the Nkam in the south (Ménoua, Makombé, Ngoum and Mwanké) that support breeding of blackfly which transmit onchocerciasis throughout the year. The climate is equatorial of the Cameroon sub-variety in the northwestern third and equatorial of the Guinea type in the southeastern two-thirds, with a long rainy season (March-October) and a short dry season (November-February). Rainfall, moderated by the mountains, averages $1000-2000 \mathrm{~mm}$ per year. The West is one of the Cameroon's richest economic areas due primarily to its agricultural prosperity and the enterprising traditions of the Bamileke people, accounting for $90 \%$ of the total population.

\section{Selection of communities}

Surveyed communities were selected according to the availability of 1996 baseline data [28] and the results of the 2011 follow-up survey [29]. In 1996, a baseline survey was conducted in 38 communities belonging to six HD at that time, 30 of them being mesoendemic $(35 \% \leq$ prevalence $<$ $60 \%$ ) or hyperendemic (prevalence $\geq 60 \%$ ). Among the later, 12 communities were selected and evaluated in follow-up surveys in 2005, 2006 or 2011. From unevaluated communities, we selected 13 presenting the highest

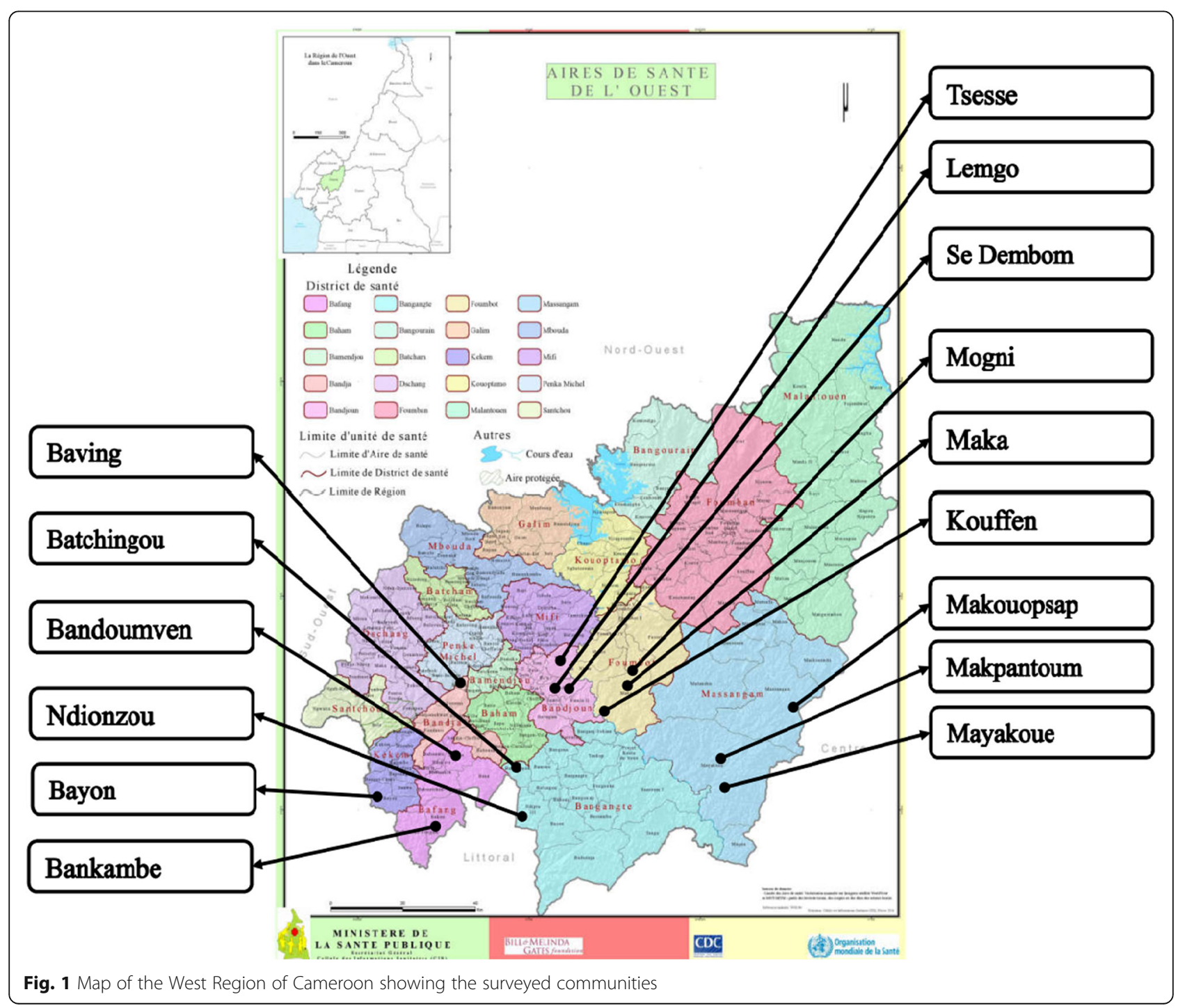


microfilaridermia prevalence and/or community microfilarial load (CMFL) distributed throughout the region and belonging to seven HD as follows: Bafang (2); Bandja (1); Bandjoun (3); Bangangté (2); Foumbot (3); Kékem (1); Massangam (1). We added the community Makouopsap that was evaluated only in 2011, and showed a high prevalence (60\%), and the community Makpantoum, never evaluated, both belonging to the Massangam HD (Table 1; Fig. 1).

\section{History of mass treatment with ivermectin}

The treatment started in 1996 in the region with the support of Carter Center and Lions Club International Foundation, as a community based treatment with an annual dose of ivermectin. However, according to the National Onchocerciasis Control Programme (NOCP), CDTI started in 2000 in the region with a progressive enrollment of communities [30]. So, these communities received at least 15 rounds of mass drug administration, respectively. The therapeutic coverage achieved calculated over the total population was only $50 \%$ in 2000 and, from 2001 it was at least $75 \%$ as illustrated in Fig. 2. During the last five years of treatment campaigns, the treatment coverage was above $80 \%$.

\section{Study design and patients}

A cross-sectional survey was conducted in May 2015 in 15 communities of the Bafang (2), Bandja (1), Bandjoun (3), Bangangté (2), Foumbot (3), Kékem (1) and Massangam (3) health districts, nine months after the previous annual ivermectin distribution. All individuals, either permanent residents or who had already lived for at least five years in the community and aged five years or more were eligible for this survey. All volunteers underwent clinical and parasitological examinations. In addition, individual adherence to ivermectin treatment was also assessed.

\section{Clinical examination}

Each participant was examined for skin disease and nodules. The searched cutaneous signs were depigmentation, onchodermatitis (acute, chronic and lichenified), hanging groin and skin atrophy. Participants were scored as 'positive' or 'negative' to each cutaneous sign. Nodule palpation was performed in a closed but well-illuminated room. Qualified and certified staff performed the palpation on partially disrobed participants while paying particular attention to bony prominences of the torso, iliac crests and upper trochanter of the femurs. Onchocercal nodules were identified clinically as mobile masses beneath the skin, firm and painless [31-33]. Results were ranked as 'positive' or 'negative', and if positive, the number and location of all palpable onchocercal nodules were recorded.

\section{Parasitological examination}

Immediately following the nodule palpation, two skin snips were taken from each posterior iliac crest using a $2 \mathrm{~mm}$ corneoscleral punch (Holth-type). The skin samples were immediately placed, separately, into wells of microtitration plates containing a sterile normal saline solution. After $24 \mathrm{~h}$ incubation at room temperature, the

Table 1 Baseline data in selected communities

\begin{tabular}{|c|c|c|c|c|c|c|c|c|c|c|}
\hline \multirow{2}{*}{$\begin{array}{l}\text { Health } \\
\text { district }\end{array}$} & \multirow[t]{2}{*}{ Community } & \multicolumn{5}{|c|}{ Kamgno 1996 (baseline data) [28] } & \multicolumn{4}{|c|}{ Katabarwa 2011 [29] } \\
\hline & & N1 & $\begin{array}{l}\text { Weighted nodule } \\
\text { prevalence (\%) }\end{array}$ & N2 & $\begin{array}{l}\text { Weighted } \mathrm{mf} \\
\text { prevalence (\%) }\end{array}$ & CMFL (mf/ss) & N1 & $\begin{array}{l}\text { Crude nodule } \\
\text { prevalence (\%) }\end{array}$ & N2 & $\begin{array}{l}\text { Crude mf } \\
\text { prevalence (\%) }\end{array}$ \\
\hline \multirow[t]{2}{*}{ Bafang } & Bandoumven & 29 & 51.7 & 64 & 65.1 & 5.79 & & & & \\
\hline & Bankambe & 25 & 64.0 & 122 & 75.8 & 3.75 & & & & \\
\hline Bandja & Baving & 31 & 35.5 & 45 & 75.3 & 7.10 & & & & \\
\hline \multirow[t]{3}{*}{ Bandjoun } & Lemgo & 28 & 71.4 & 43 & 85.5 & 13.19 & & & & \\
\hline & Sé-Dembom & 32 & 81.3 & 51 & 82.4 & 26.69 & & & & \\
\hline & Tsessè & 29 & 75.9 & 42 & 85.6 & 13.18 & & & & \\
\hline \multirow[t]{2}{*}{ Bangangté } & Batchingou & 29 & 75.9 & 84 & 72.3 & 7.67 & 247 & 11.7 & 247 & 18.2 \\
\hline & Ndionzou & 24 & 95.8 & 107 & 90.2 & 7.90 & & & & \\
\hline \multirow[t]{3}{*}{ Foumbot } & Kouffen & 27 & 88.9 & 33 & 81.8 & 19.17 & & & & \\
\hline & Maka & 30 & 76.7 & 53 & 76.9 & 20.16 & & & & \\
\hline & Mogni & 29 & 79.3 & 38 & 78.3 & 33.16 & & & & \\
\hline Kékem & Bayon & 27 & 55.6 & 127 & 83.5 & 6.79 & & & & \\
\hline \multirow[t]{3}{*}{ Massangam } & Makouopsap & nd & nd & nd & nd & nd & 99 & 43.4 & 99 & 59.6 \\
\hline & Makpantoum & nd & nd & nd & nd & nd & nd & nd & nd & nd \\
\hline & Mayakoué & 25 & 88.0 & 61 & 91.1 & 18.76 & & & & \\
\hline
\end{tabular}

Abbreviations: N1 Number of persons with clinical examination, N2 Number of persons with parasitological examination, $m f$ microfilaria, nod nodule, CMFL community microfilarial load (microfilariae/skin snip), nd not done 


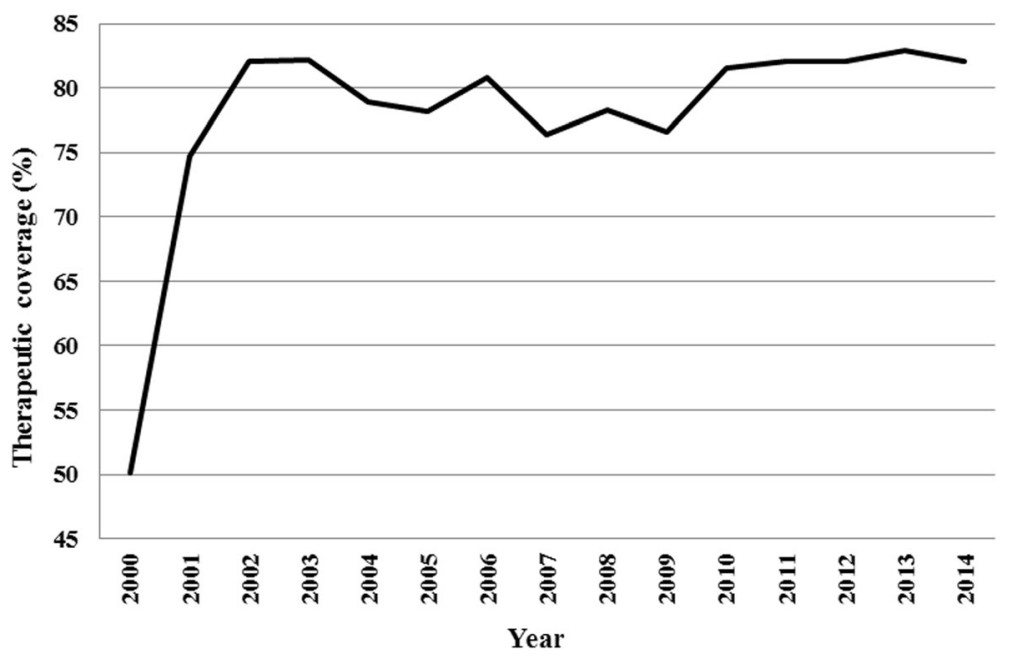

Fig. 2 Therapeutic coverage of community-directed treatment with ivermectin in the West Region between 2000 and 2014

skin snips were removed and the fluid from each well was examined under low magnification $(40 \times)$ by trained laboratory technicians [34]. For positive results, the microfilariae were counted and the individual microfilarial densities were expressed as the arithmetic mean number of microfilariae in the two skin snips (mf/ss).

\section{Assessment of the individual adherence to ivermectin mass treatment}

Individual adherence to ivermectin mass treatment was assessed by asking to each participant if he/she swallowed ivermectin tablets during each of the previous five years (including the last CDTI-campaign). Ivermectin tablets were presented to the participants to make sure that the interview was targeting the right treatment. Participant answers were recorded on an individual form as "yes", "no" or cannot remember for each of the last five years.

\section{Data analysis}

All relevant data (clinical signs, nodule, $\mathrm{mf}$ count, and adherence to ivermectin mass treatment) were recorded into a purpose-built Microsoft Access database and subsequently exported into STATA 13 for statistical analysis. All analyses were weighted proportionally to age and gender distribution in the population, according to 2015 national demographic data projections (Additional file 1: Tables S1-S3) [35]. Cutaneous signs, nodules and microfilaridermia prevalences were expressed as the proportion of infected or affected individuals with the $95 \%$ exact confidence interval (CI). When the microfilarial count was positive, the intensity of infection was computed as the geometric mean and its 95\% CI. The community microfilarial load (CMFL) is defined as the geometric mean number of microfilariae per skin snip $(\mathrm{mf} / \mathrm{ss})$ among adults aged 20 years or more. It was calculated using a $\log (\mathrm{x}+1)$ transformation $\left(\right.$ CMFL $\left.=\mathrm{e}^{\frac{1}{\mathrm{~N}} \sum \ln (\mathrm{x}+1)}-1\right)$ where $\mathrm{x}$ is the individual microfilarial density, and $\mathrm{N}$ the total number of individuals aged 20 years and above. The therapeutic coverages were calculated using the total number of participants in each community. Frequencies were compared using Chi-square tests. Mean intensities of infection were compared between age and gender subgroups using ANOVA with $F$-tests or $t$-tests. A $P$-value $<0.05$ was considered as statistically significant.

\section{Results}

In the seven HD, 2058 individuals were examined among whom $55.2 \%$ were women. The mean age was $28.4 \pm 22.2$ years and, higher in women $30.1 \pm 22.4$ than in men $26.3 \pm 21.9$ (unpaired Student's $t=3.80, P<0.001$ ).

\section{Prevalence and intensity of infection}

The weighted prevalence of microfilaridermia was 5.5\% (95\% CI: 4.6-6.7) in the whole group and varied from $4.7 \%$ in women to $6.5 \%$ in men $\left(\chi^{2}=3.0, d f=1\right.$, $P=0.08)$. The weighted prevalence of nodule presence was $2.1 \%$ (95\% CI: $1.6-2.8)$ and varied from $2.6 \%$ in women to $4.8 \%$ in men $\left(\chi^{2}=2.0, d f=1, P=0.16\right)$. The weighted prevalence of cutaneous signs presence was $1.7 \%$ (95\% CI: $1.3-2.1$ ) and varied from $1.1 \%$ in men to $2.2 \%$ in women $\left(\chi^{2}=3.6, d f=1, P=0.058\right)$. Among microfilaridermia carriers, the geometric mean was 3.2 $\mathrm{mf} / \mathrm{ss}$ (SD: 4.3) and varied from $3.0 \mathrm{mf} / \mathrm{ss}$ (SD: 4.9) in female to $3.5 \mathrm{mf} / \mathrm{ss}$ (SD: 3.9$)$ in male $(t=1.13, d f=121$, $P=0.26)$. Among nodule carriers, the geometric mean was 1.3 nodules per carrier (SD: 1.5) with no variation between males 1.3 (SD: 1.5) and females 1.3 (SD: 1.5) $(t=-0.13, d f=69, P=0.90)$. 
Regarding age groups, the weighted prevalences of microfilaridermia varied respectively from $4.0 \%$ in $5-9$ years old to $11.6 \%$ in $40-49$ years old, with significant differences among age groups $\left(\chi^{2}=20.3, d f=6, P=0.002\right)$. The presence of nodules increased with age, with weighted prevalences from $0.2 \%$ in $10-19$ years old to $8.2 \%$ in $50-59$ years old $\left(\chi^{2}=68.3, d f=6, P<0.001\right)$. For cutaneous signs, there was a large difference between $<40$ years and $\geq 40(0.4 \% v s$ $10.8 \%$; $\left.\chi^{2}=145.3, d f=1, P<0.001\right)$. The geometric mean of microfilaridermia among positive cases was higher in 20-29 years-old participants and decreased with age (ANOVA: $\left.F_{(6,116)}=2.32, P=0.04\right)$, while there was no difference among age groups for nodule geometric means (ANOVA: $F_{(6,64)}=0.95, P=0.46$ ) (Table 2). In the 30 children aged under 10 years we examined in Makouopsap, the weighted prevalences were $49.9 \%$ (95\% CI: 32.0-67.9) for microfilaridermia and 13.3\% (95\% CI: 1.1-25.5) for nodule presence, respectively. In this age group, 15 out of 19 positive children overall for microfilaridermia and 4 out of 8 carrying nodules came from Makoupsap.

In surveyed communities, the weighted prevalences of microfilaridermia varied from $0 \%$ (Lemgo, Tsesse, Ndionzou, Kouffen) to $41.6 \%$ (Makouopsap), with 11 (73.3\%) communities having less than 5\%. Except the community Makouopsap which had a prevalence of $41.6 \%$, all the surveyed communities were below 15\%. A significant reduction in microfilaridermia prevalence was observed (84.7-100\%) in all the 13 communities, as compared to baseline data (Fig. 3). The CMFL in all the surveyed communities also significantly dropped by $98-$ $100 \%$, from $3.75-33.16 \mathrm{mf} / \mathrm{ss}$ in 1996 to $0-0.94 \mathrm{mf} / \mathrm{ss}$ in 2015 (Fig. 4). The weighted prevalences of nodule presence varied from 0\% (Bandoumven, Baving, Ndionzou) to $14.4 \%$ (Makouopsap), with 14 (93.3\%) communities having less than $5 \%$. For cutaneous signs presence, the weighted prevalences varied from $0 \%$ to $13.3 \%$, with 13 (86.7\%) communities having less than $5 \%$ (Table 3). Onchocercal skin lesions were more frequent in two communities (Baving and Ndionzou) where lower limb depigmentation and chronic onchodermatitis were found (Table 3).

Most palpable nodules were localized in the pelvic grid, the chest, the head and the knee, with half of them found in the pelvic grid (Fig. 5).

\section{Adherence to ivermectin mass treatments in surveyed communities}

The overall weighted therapeutic coverage in 2014 was 69.4\% (95\% CI: 67.4-71.4), with important variations across communities ranging from 35.9\% (95\% CI: 27.3-44.5) in Tsesse (Bandjoun HD) to $89.7 \%$ (95\% CI: 83.8-95.5) in Kouffen (Foumbot HD). Only 39.3\% (95\% CI: 27.6-50.9) of participants declared to have swallowed ivermectin tablets each year during the past five years, ranging from $8.3 \%$ (95\% CI: 4.9-11.7) in Maka (Foumbot HD) to $69.3 \%$ (95\% CI: 57.2-81.4) in Mayakoue (Massangam HD). The reported adherence to treatment increased significantly with age since

Table 2 Weighted prevalence of microfilaridermia, nodules and cutaneous signs presence according to gender and age groups

\begin{tabular}{|c|c|c|c|c|c|c|c|c|c|}
\hline & \multirow[t]{2}{*}{$N$} & \multicolumn{3}{|c|}{ Parasitological examination } & \multicolumn{5}{|c|}{ Clinical examination } \\
\hline & & $\mathrm{mf}+(n)$ & $\begin{array}{l}\text { Weighted mf } \\
\text { prevalence (\%) }\end{array}$ & $\begin{array}{l}\text { Geometric mean } \\
\text { of } \mathrm{mf} \text { in carriers } \\
(\mathrm{mf} / \mathrm{ss} \pm \mathrm{SD})\end{array}$ & Nodule $+(n)$ & $\begin{array}{l}\text { Weighted nodule } \\
\text { prevalence (\%) }\end{array}$ & $\begin{array}{l}\text { Geometric mean of } \\
\text { nodule in carriers } \pm S D\end{array}$ & cut $+(n)$ & $\begin{array}{l}\text { Weighted cut } \\
\text { prevalence (\%) }\end{array}$ \\
\hline \multicolumn{10}{|l|}{ Sex } \\
\hline Female & 1136 & 57 & 4.7 & $3.0 \pm 4.9$ & 29 & 1.7 & $1.3 \pm 1.5$ & 56 & 2.2 \\
\hline Male & 922 & 68 & 6.5 & $3.5 \pm 3.9$ & 44 & 2.6 & $1.3 \pm 1.5$ & 24 & 1.1 \\
\hline Total & 2058 & 125 & 5.5 & $3.2 \pm 4.3$ & 73 & 2.1 & $1.3 \pm 1.5$ & 80 & 1.7 \\
\hline \multicolumn{10}{|c|}{ Age categories (years) } \\
\hline $5-9$ & 472 & 19 & 4.0 & $4.7 \pm 4.7$ & 8 & 1.7 & $1.2 \pm 1.4$ & 1 & 0.2 \\
\hline $10-19$ & 609 & 27 & 4.4 & $2.5 \pm 4.8$ & 1 & 0.2 & $1.0 \pm(-)^{b}$ & 0 & 0 \\
\hline $20-29$ & 156 & 16 & 10.1 & $6.9 \pm 2.9$ & 5 & 3.2 & $1.2 \pm 1.4$ & 1 & 0.7 \\
\hline $30-39$ & 173 & 13 & 7.5 & $1.5 \pm 2.4$ & 14 & 8.0 & $1.4 \pm 1.6$ & 6 & 3.4 \\
\hline $40-49$ & 180 & 21 & 11.6 & $3.6 \pm 5.1$ & 11 & 6.1 & $1.3 \pm 1.5$ & 13 & 7.2 \\
\hline $50-59$ & 147 & 12 & 8.3 & $1.4 \pm 2.4$ & 12 & 8.2 & $1.0 \pm 1.0$ & 16 & 10.8 \\
\hline $60+$ & 297 & 15 & 5.1 & $2.8 \pm 4.4$ & 20 & 6.6 & $1.4 \pm 1.8$ & 41 & 14.0 \\
\hline Total & 2034 & 123 & 5.5 & $3.2 \pm 4.3$ & 71 & 2.1 & $1.3 \pm 1.5$ & 78 & 1.7 \\
\hline
\end{tabular}

Abbreviations: $N$ number examined, $M f+(n)$ number with microfilaria positive skin snip, Nod $+(n)$ number of nodule carriers, Cut $+(n)$ number with cutaneous sign, SD standard deviation

an each gender category, the indices were adjusted on age; In each age category, the indices were adjusted on sex; in the total populations, indices were adjusted on sex and age

${ }^{\text {b }}$ Standard deviation not calculated as the number of observations is 1 


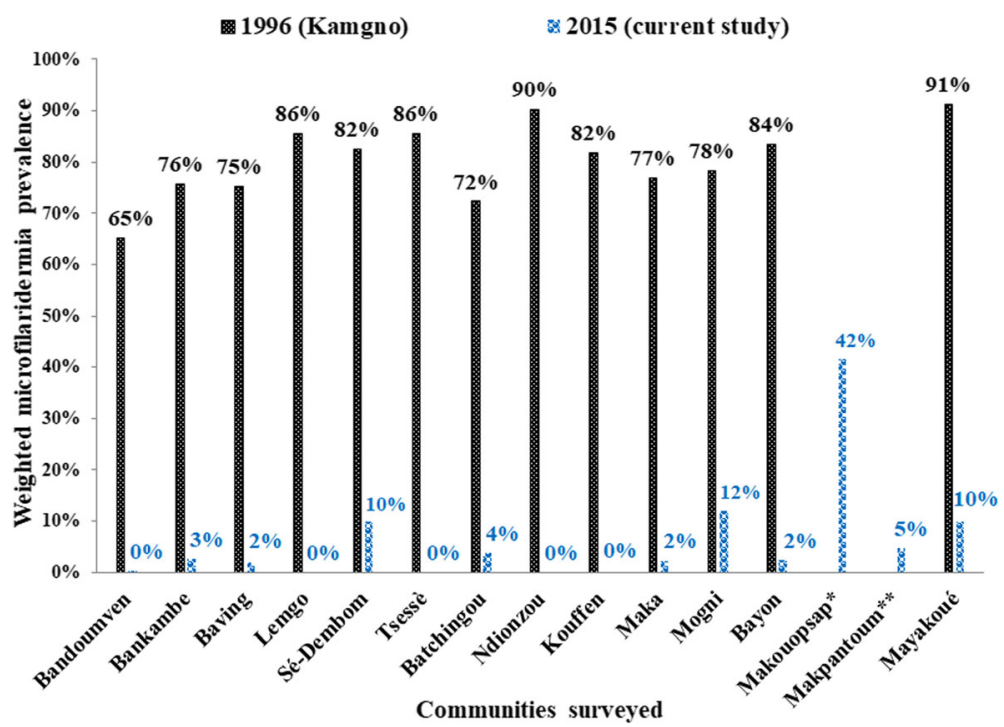

Fig. 3 Comparison of weighted microfilaridermia at baseline in 1996 and in follow-up survey in 2015 in each surveyed community. ${ }^{*}$ Community was not surveyed in 1996 but in $2011 ;{ }^{* *}$ Community was not surveyed in 1996 nor in 2011

more than $70 \%$ of participants aged 40 years and above declared having taken the treatment each year during the last five years. More than $82 \%$ reported to have taken the treatment in 2014. More than one out of four participants (26.1\%; 95\% CI: 23.9-28.3) declared that they had not taken the treatment during the last five years. These non-adherent participants are mainly found at Bandoumven (Bafang HD), Lemgo and Tsesse (Bandjoun HD), Ndionzou (Bangangte HD), Maka and Mogni (Foumbot HD) with at least $30 \%$ in each community who declared not having taken the treatment (Figs. 6 and 7). The microfilaridermia prevalence was not, in general, associated with treatment adherence $\left(\chi^{2}=3.8, d f=5, P=0.58\right)$, even in Makouopsap where the endemicity level was the highest $\left(\chi^{2}=3.0, d f=5, P=0.70\right)$. The geometric mean of microfilaria among carriers was not associated with treatment adherence (ANOVA: $F_{(5,117)}=2.18, P=0.06$ ).

\section{Discussion}

The objective of the present survey was to assess the progress made towards the elimination of onchocerciasis in the West CDTI project by assessing unevaluated communities

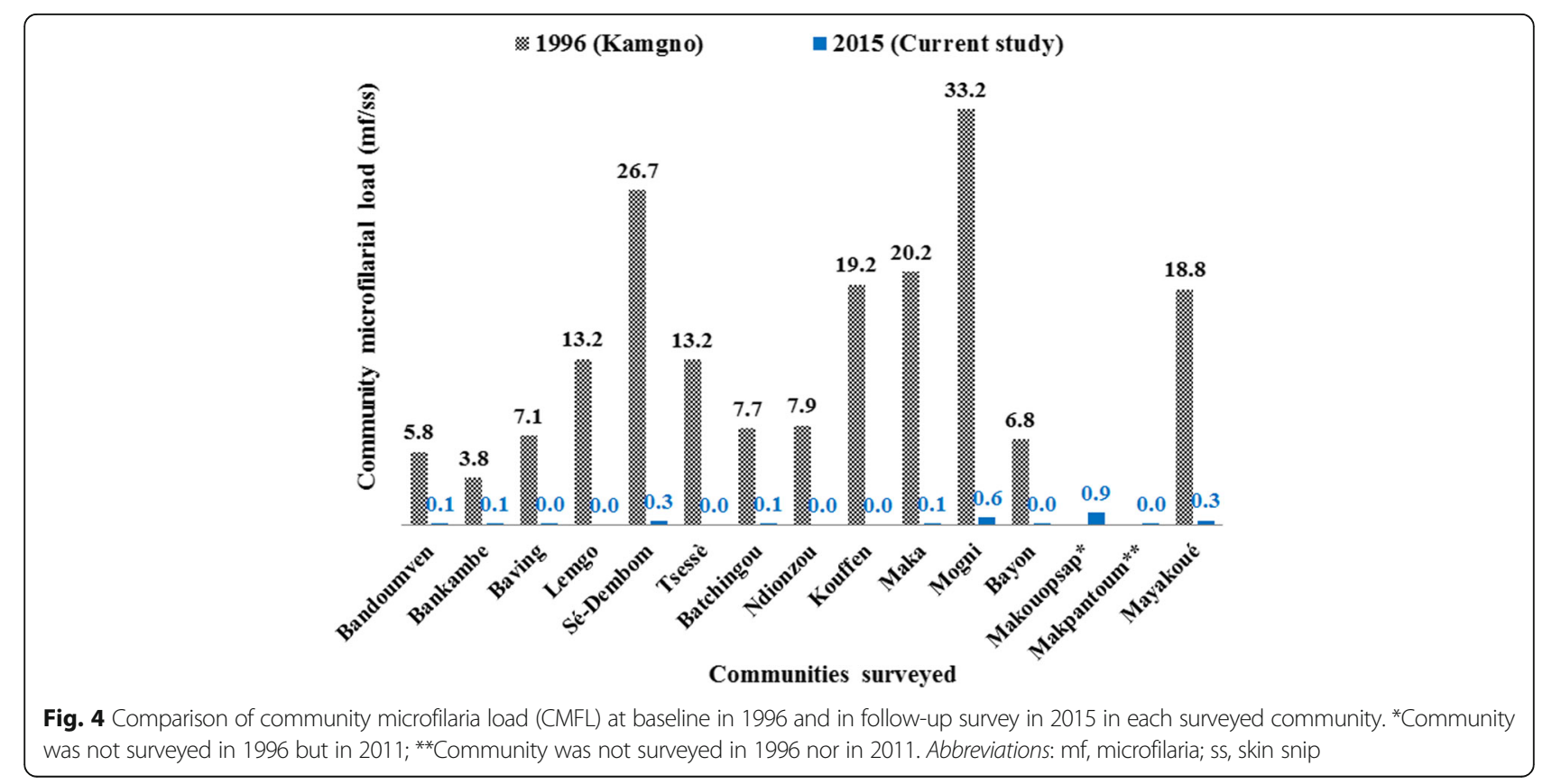


Table 3 Weighted prevalence of microfilaridermia, nodules and cutaneous signs presence in each surveyed community

\begin{tabular}{|c|c|c|c|c|c|c|c|c|c|c|}
\hline \multirow[b]{2}{*}{$\begin{array}{l}\text { Health } \\
\text { district }\end{array}$} & \multirow[b]{2}{*}{ Community } & \multirow[b]{2}{*}{$N$} & \multicolumn{3}{|c|}{ Parasitological examination } & \multicolumn{5}{|c|}{ Clinical examination } \\
\hline & & & $m f+(n)$ & $\begin{array}{l}\text { Weighted mf } \\
\text { prevalence (\%) }\end{array}$ & $\begin{array}{l}\text { Geometric mean } \\
\text { of } \mathrm{mf} \text { in carriers } \\
(\mathrm{mf} / \mathrm{ss} \pm \mathrm{SD}\end{array}$ & $\mathrm{Nod}+(n)$ & $\begin{array}{l}\text { Weighted nodule } \\
\text { prevalence (\%) }\end{array}$ & $\begin{array}{l}\text { Geometric } \\
\text { mean of nodule } \\
\text { in carriers } \pm S D\end{array}$ & cut $+(n)$ & $\begin{array}{l}\text { Weighted cut } \\
\text { prevalence (\%) }\end{array}$ \\
\hline \multirow[t]{2}{*}{ Bafang } & Bandoumven & 125 & 1 & 0.3 & $22.0 \pm(-)^{b}$ & 0 & 0 & - & 7 & 1.7 \\
\hline & Bankambe & 203 & 9 & 2.6 & $1.3 \pm 2.9$ & 11 & 2.9 & $1.3 \pm 1.4$ & 0 & 0 \\
\hline Bandja & Baving & 136 & 3 & 1.8 & $1.7 \pm 1.3$ & 0 & 0 & - & 25 & 9.1 \\
\hline \multirow[t]{3}{*}{ Bandjoun } & Lemgo & 75 & 0 & 0.0 & - & 3 & 1.1 & $1.0 \pm 1.0$ & 0 & 0 \\
\hline & Se Dembom & 173 & 17 & 9.8 & $5.2 \pm 4.2$ & 1 & 0.2 & $1.0 \pm(-)^{b}$ & 1 & 0.5 \\
\hline & Tsesse & 123 & 0 & 0.0 & - & 1 & 0.4 & $1.0 \pm(-)^{b}$ & 0 & 0 \\
\hline \multirow[t]{2}{*}{ Bangangté } & Batchingou & 139 & 6 & 3.7 & $2.9 \pm 2.7$ & 10 & 2.7 & $1.3 \pm 1.8$ & 2 & 0.6 \\
\hline & Ndionzou & 141 & 0 & 0.0 & - & 0 & 0 & - & 43 & 13.3 \\
\hline \multirow[t]{3}{*}{ Foumbot } & Kouffen & 107 & 0 & 0.0 & - & 5 & 2.5 & $1.9 \pm 1.8$ & 0 & 0 \\
\hline & Maka & 207 & 6 & 2.2 & $0.9 \pm 2.1$ & 2 & 0.9 & $1.0 \pm 1.0$ & 0 & 0 \\
\hline & Mogni & 96 & 12 & 12.0 & $4.0 \pm 3.3$ & 6 & 3.9 & $1.4 \pm 1.8$ & 0 & 0 \\
\hline Kékem & Bayon & 231 & 6 & 2.3 & $2.3 \pm 2.8$ & 3 & 0.5 & $1.0 \pm 1.0$ & 0 & 0 \\
\hline \multirow[t]{3}{*}{ Massangam } & Makouopsap & 123 & 53 & 41.6 & $3.7 \pm 5.4$ & 26 & 14.4 & $1.3 \pm 1.4$ & 2 & 1.1 \\
\hline & Makpantoum & 114 & 5 & 4.7 & $1.3 \pm 1.9$ & 3 & 2.4 & $1.0 \pm 1.0$ & 0 & 0 \\
\hline & Mayakoue & 65 & 7 & 9.8 & $5.3 \pm 3.9$ & 2 & 2.6 & $1.4 \pm 1.6$ & 0 & 0 \\
\hline Total & & 2058 & 125 & 5.5 & $3.2 \pm 4.3$ & 73 & 2.1 & $1.3 \pm 1.5$ & 80 & 24.5 \\
\hline
\end{tabular}

Abbreviations: $N$ number examined, $M f+(n)$ number with microfilaria positive skin snip, Nod $+(n)$ number of nodule carriers, Cut $+(n)$ number with cutaneous sign, $S D$ standard deviation

a In each gender category, the indices were adjusted on age; In each age category, the indices were adjusted on sex; in the total populations, indices were adjusted on sex and age

${ }^{\mathrm{b}}$ Standard deviation not calculated as the number of observations is 1

where the highest endemicity level were found in 1996, before the launch of control measures. This assessment was based on previous APOC's conceptual framework for onchocerciasis elimination as it was conducted before the publication of the new 2016 WHO revised guidelines on stopping mass drug administration (MDA) and verifying elimination which advocate xenomonitoring and serology.

In 2015, after more than 15 years of ivermectin mass treatment, we observed a great reduction in microfilaridermia prevalence in all the 13 communities with baseline endemicity data, but still above the expected level at Makouopsap (Massangam HD) $(\leq 20 \%$ for a pretreatment endemicity $\geq 80 \%$ assuming a therapeutic coverage of $65 \%)[26,36]$. In line with the observed decrease in the mf prevalences, the intensity of infection had considerably decreased in 2015, with CMFL below $1 \mathrm{mf} / \mathrm{ss}$ in all communities, even at Makouopsap.

The Makouopsap focus is close to the Mbam river, a fast-flowing river which also crossed the Bafia HD (Centre Region) where recent surveys found a microfilaridermia weighted prevalence as high as $57 \%$ in the community Ngongol [37]. Blackfly breeding sites located along the river contribute to maintain high vector densities and continuing transmission as it was previously demonstrated for first-line communities [38]. As also observed in some foci of the Bafia HD, the Makouopsap focus had the highest prevalence of microfilaridermia and nodule observed in less than 10-year-old children, born after the launch of the programme. This is a strong evidence of ongoing active transmission which could later be confirmed by OV-16 serology as recommended by the new WHO guidelines [27]. A joined innovative strategy (semi-annual ivermectin treatment, vector control) between the West and the Centre CDTI-projects, led by the National Onchocerciasis Control Programme (NOCP) should be implemented to definitively tackle the persistence of the disease across the bordering districts. Walker et al. [39] highlighted the potential importance of vector control in high-transmission settings as a complementary intervention strategy.

In the other surveyed communities, there is an encouraging progress towards the elimination of the disease with a less than 5\% weighted microfilaridermia prevalence in $11 / 14$ communities, however not enough to initiate a decrease in ivermectin distribution according to the new WHO guidelines [27]. As underlined in the guidelines, the skin snip sensitivity is low especially in newly infected person and after several ivermectin rounds which considerably reduce the microfilarial load. It is possible that the true prevalences are higher than those observed in this study as also mentioned by Bottomley et al. [40] who found that this sensitivity 


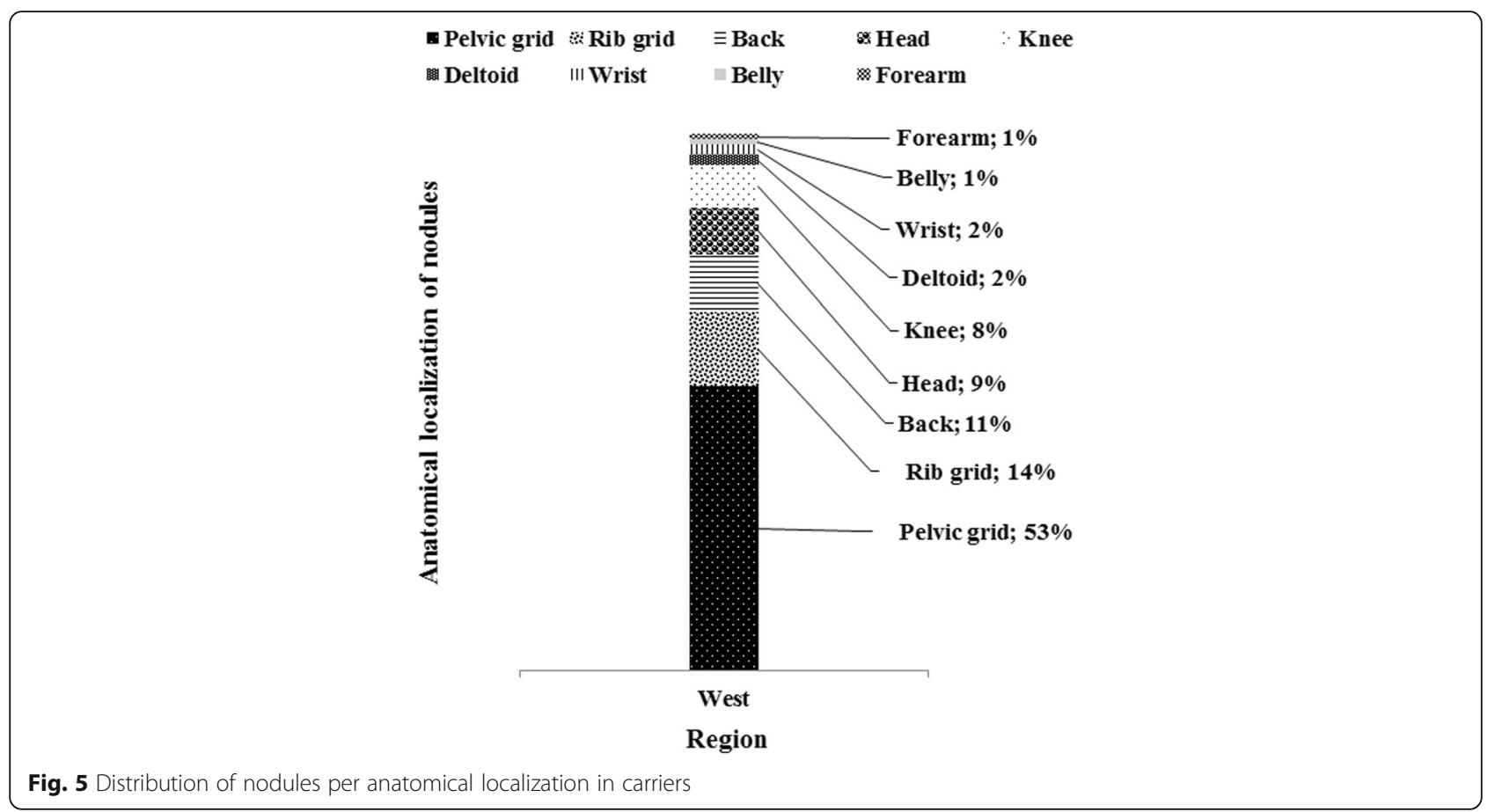

increases with the number of skin snips taken. Therefore, the NOCP, the communities and the different stakeholders involved in the control programme should be encouraged to improve and sustain their efforts.

The progress observed is threatened by many factors like (i) the vector burden, (ii) the low adherence to ivermectin treatment especially in younger persons, and (iii) the presence of the disease in children. We have not performed entomological surveys, but as the epidemiological situation has not changed at Makouopsap, we can also assume that the entomological situation remained unchanged too, especially as no vector control measure was implemented. We can rely on results reported by Katabarwa et al. [29, 41] in 2011 with an

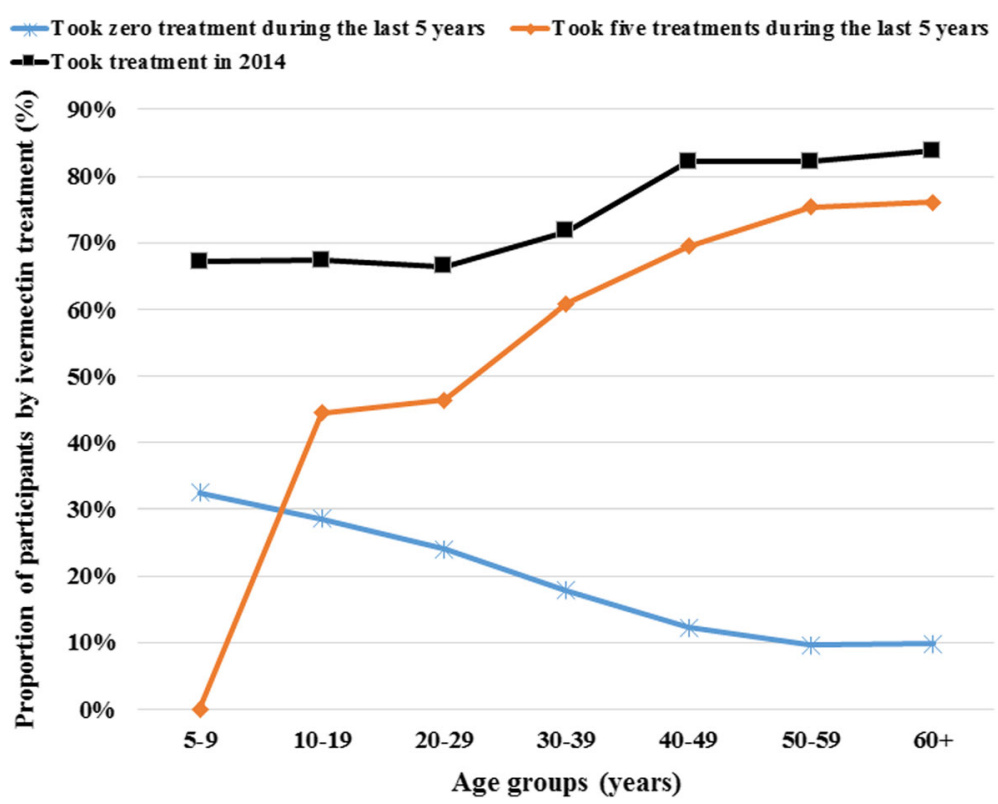

Fig. 6 Therapeutic adherence to ivermectin treatment of participants per age groups 

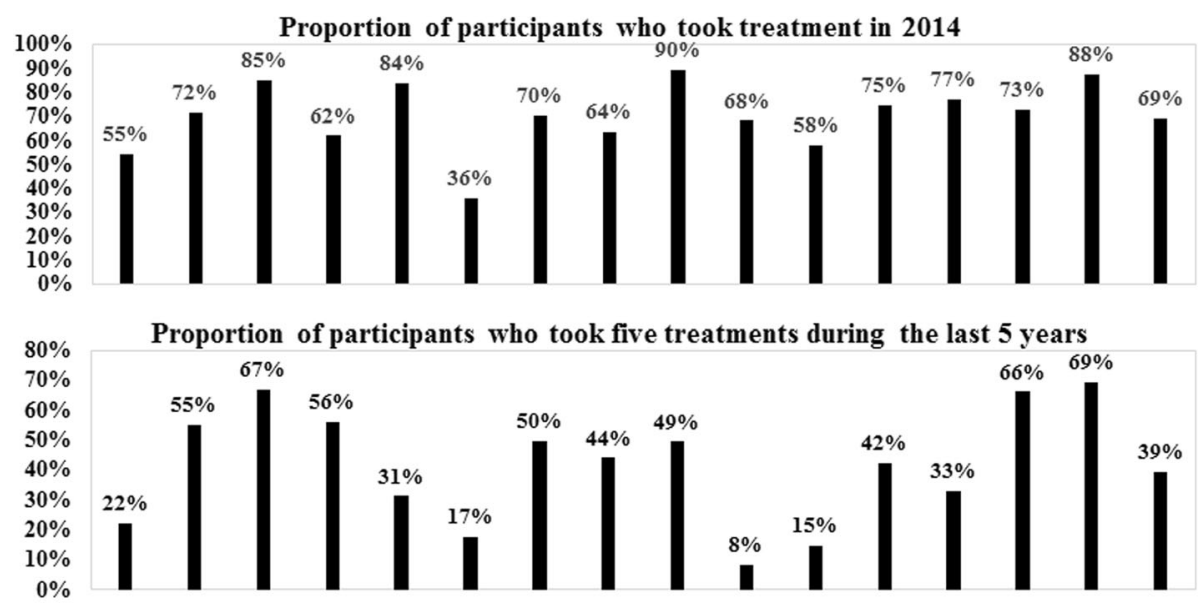

Proportion of participants who took zero treatment during the last 5 years

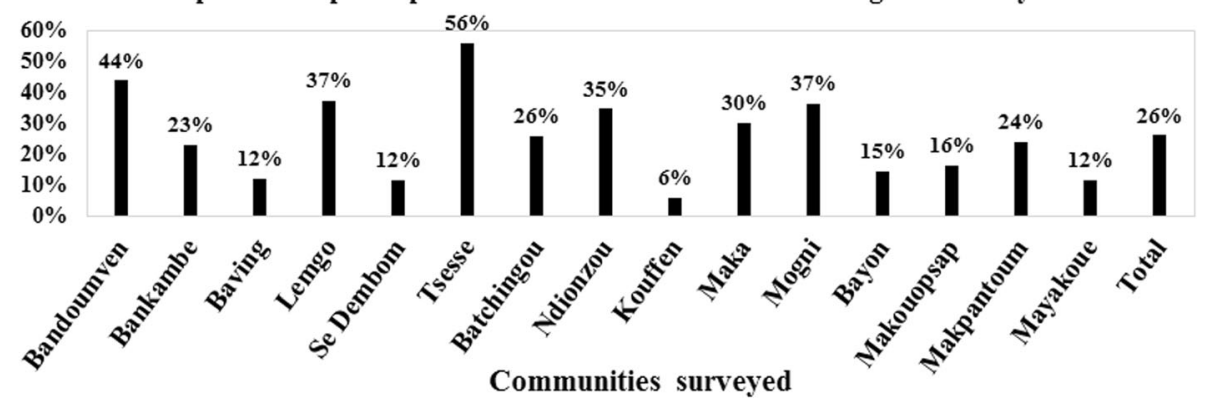

Fig. 7 Therapeutic adherence to ivermectin treatment of participants in surveyed communities

annual biting rate of 125,360 and an annual transmission potential of 310 in that locality. Considering the potential flight range of blackflies which can reach $500 \mathrm{~km}$ as observed in the reinvasion of some countries after vector control measures in West Africa [42], the focus of Makoupsap can be the source of reinfestation or maintenance of infection in the entire West Region and the neighboring Regions. Only 39\% of the participants declared having taken five treatments during the last five years. Such low adherence to treatment is also a threat to the elimination of the disease. At the same time, about $26 \%$ of the participants did not take a treatment during that period. The low adherence observed in the less than 30-years group, not feeling the necessity to take a drug for a disease that they do not experience in the day-to-day life, constitutes an important hindrance in the success of the programme. With the observed adherence, the likelihood for the programme to achieve elimination of the disease by 2025 is quite low. Even though this survey was conducted nine months after the previous treatment, we believe that our results regarding the therapeutic coverage and the adherence are reliable because ivermectin tablets are special, by both their physical presentation (small and white) and their delivery strategy. So, the likelihood to confuse them with other drugs or interventions is quite low. Previous studies have reported accurate recall of populations when compared to the data from CDTI collected in treatment registry [43-45]. The presence of the disease in less than 10-year-old children is another threat as it means that the adult worms they carried, still have a lifespan of at least 5 to 10 years, constituting a source of reinfestation.

The oldest participants have more nodules than their youngest counterparts due to their prolonged exposure to the bites of blackflies, meanwhile their adherence to treatment could explain their lowest intensity of infection. This adherence is probably motivated by their awareness about the consequences of the disease.

The localization of nodules was comparable to previous studies [31-33, 37]. Onchocercal skin disease was more frequent in two communities (Baving and Ndionzou) where lower limb depigmentation, acute and chronic onchodermatitis were found.

\section{Conclusions}

After more than 15 years of CDTI, except at Makouopsap, there is an important progress towards the elimination of onchocerciasis in the communities surveyed as part of this study. Additional efforts should be made to improve the CDTI adherence in all communities to maintain the achievement or greatly reduce the prevalence and the 
microfilarial densities to eliminate this debilitating disease. Innovative strategy like semi-annual ivermectin treatment plus a vector control strategy or the adjunction of a vector control strategy to the current annual treatment should be implemented at least in the bordering districts of the Centre and West Regions. Similar alternative interventions should also be implemented in other part of the country where the high prevalences of the disease persist to curb its progression in the sight of its elimination. Further studies targeting community therapeutic coverage, CDTI process and entomological studies in the Massangam district would provide better insights into our understanding of the persistence of the disease in that health district.

\section{Additional file}

Additional file 1: Table S1. National demographic projections in 2015. Table S2. National demographic projections in 2015 for eligible persons. Table S3. Summary of national demographic projections in 2015 in eligible persons. (DOCX $26 \mathrm{~kb}$ )

\section{Abbreviations}

APOC: African Programme for Onchocerciasis Control; ARES-CCD: Académie de Recherche et d'Enseignement Supérieur-Commission de la Coopération au Développement, Belgique; CDD: Community-directed distributors; CDTI: Community-directed treatment with ivermectin; Cl: Confidence interval; CMFL: Community microfilarial load; CRFilMT: Centre for Research on Filariasis and other Tropical Diseases, Cameroon; HD: Health district; MDA: Mass drug administration; mf/ss: Microfilariae per skin snip; NOCP: National Onchocerciasis Control Programme, Cameroon; WHO: World Health Organization

\section{Acknowledgements}

The authors thank the lab technicians Bopda Jean, Batif Emmanuel and Mbickmen Tchana Steve who helped us to collect and analyze skin snips, the staff of the seven health districts, the heads of the surveyed communities, and the participants for their cooperation.

\section{Funding}

This study was funded by the Belgian university cooperation (www.ares-ac.be/fr/ cooperation-au-developpement) through the PRD2013 collaborative project between Université catholique de Louvain, Université Libre de Bruxelles, the University of Buea, the Centre for Research on Filariasis and other Tropical Diseases (CRFilMT) and the Ministry of Public Health of Cameroon.

\section{Availability of data and materials}

The datasets supporting the conclusions of this article can be obtained upon request.

\footnotetext{
Authors' contributions

GRK participated to the design of experiments, collected field data, performed statistical analyses and drafted the manuscript. FDD participated to the design of experiments and helped draft the manuscript. HND participated to the design of experiments, help in the statistical analyses and drafted the manuscript. BDB provided previous data and helped draft the manuscript. SG participated in the conception and the design of the study, and helped draft the manuscript. JS conceived the study, designed the experiments, and helped draft the manuscript. JK conceived and the coordinated the study, designed the experiments, and helped draft the manuscript. AR conceived the study, designed the experiments, and helped draft the manuscript. All authors read and approved the final manuscript.
}

\section{Ethics approval and consent to participate}

An ethical clearance was obtained from the National Ethics Committee for Human Health Research (N²015/01/543/CE/CNRESH/SP) and an administrative authorization was granted by the Ministry of Public Health of Cameroon (№31-1315) prior to the beginning of the surveys. The study was also approved by the Ethics committee of the Medical Faculty of Université catholique de Louvain, Belgium. Objectives and schedules of the study were explained to community leaders and to all eligible individuals. Because of low literacy rate in most of the surveyed communities, a written agreement was not requested. Verbal agreements were obtained from those who agreed to participate, under the discretion of community leaders. Approval of parents or legal guardians of minors was obtained before any procedure. The study supervisor was responsible to record agreements and attribute individual code to each participant for anonymous data analysis. Participation was entirely voluntary and any individual (or parent of a child) was free to opt out of examination without fear of retaliation from their community leaders and programme personnel.

Consent for publication

Not applicable.

\section{Competing interests}

The authors declare that they have no competing interests.

\section{Publisher's Note}

Springer Nature remains neutral with regard to jurisdictional claims in published maps and institutional affiliations.

\section{Author details}

${ }^{1}$ Ministry of Public Health, No8, Rue 3038 quartier du Lac, Yaoundé, Cameroon. ${ }^{2}$ Centre for Research on Filariasis and other Tropical Diseases (CRFilMT), P.O. Box 5797, Yaoundé, Cameroon. ${ }^{3}$ Institut de Recherche Expérimentale et Clinique, Faculté de santé publique, Université catholique de Louvain, Clos Chapelle-aux-champs 30 bte B1.30.13, BE-1200 Brussels, Belgium. Institute of Biology and Molecular Medicine, Rue des professeurs Jeener et Brachet 12 BE-6041 Gosselies, Université Libre de Bruxelles, Brussels, Belgium. ${ }^{5}$ Faculty of Medicine and Biomedical Sciences, University of Yaoundé 1, P.O. Box 1364, Yaoundé, Cameroon. ${ }^{6}$ Molecular and Cell Biology Laboratory, Department of Biochemistry and Molecular Biology, University of Buea, P.O. Box 63, Buea, Cameroon.

Received: 27 February 2017 Accepted: 19 July 2017

Published online: 03 August 2017

\section{References}

1. WHO. Progress report on the elimination of human onchocerciasis, 20152016. Wkly Epidemiol Rec. 2016;91(43):505-14.

2. Remme JHF, Feenstra P, Lever PR, Medici AC, Morel CM, Noma M, et al. Tropical diseases targeted for elimination: Chagas disease, lymphatic filariasis, onchocerciasis, and leprosy. In: Jamison DT, Breman JG, Measham AR, Alleyne G, Claeson M, Evans DB, Jha P, Mills A, Musgrove P, editors. Disease control priorities in developing countries. 2nd ed. Washington (DC): World Bank/Oxford University Press; 2006. Chapter 22.

3. Zoure HG, Noma M, Tekle AH, Amazigo UV, Diggle PJ, Giorgi E, Remme JH. The geographic distribution of onchocerciasis in the 20 participating countries of the African Programme for Onchocerciasis Control: (2) pre-control endemicity levels and estimated number infected. Parasit Vectors. 2014;7:326.

4. Plaisier AP, van Oortmarssen GJ, Remme J, Habbema JD. The reproductive lifespan of Onchocerca volvulus in West African savanna. Acta Trop. 1991;48(4):271-84.

5. Duke BO. The population dynamics of Onchocerca volvulus in the human host. Trop Med Parasitol. 1993;44(2):61-8.

6. Murdoch ME, Asuzu MC, Hagan M, Makunde WH, Ngoumou P, Ogbuagu KF et al. Onchocerciasis: the clinical and epidemiological burden of skin disease in Africa. Ann Trop Med Parasitol. 2002;96(3):283-96.

7. Murdoch ME. Onchodermatitis. Curr Opin Infect Dis. 2010;23(2):124-31.

8. Hoerauf A, Buttner DW, Adjei O, Pearlman E. Onchocerciasis. BMJ. 2003; 326(7382):207-10.

9. Tamarozzi F, Halliday A, Gentil K, Hoerauf A, Pearlman E, Taylor MJ. Onchocerciasis: the role of Wolbachia bacterial endosymbionts in parasite biology, disease pathogenesis, and treatment. Clin Microbiol Rev. 2011;24(3):459-68. 
10. Resnikoff S, Keys TU. Future trends in global blindness. Indian J Ophthalmol. 2012;60(5):387-95.

11. WHO-TDR. The involvement of community-directed distributors of ivermectin in other health and development activities - report of a multi-country study; 2003. p. 1-47. Available at http://www.who.int/tdr/publications/tdr-researchpublications/ivermect_distrib/en/. Accessed on 02 Dec 2016

12. WHO-TDR. Community directed interventions for major health problems in Africa - a multi-country study: final report 2008; 2008. p. 1-132. Available at http://www.who.int/tdr/publications/tdr-research-publications/communitydirected-interventions-health-problems/en/. Accessed on 10 Nov 2016

13. Katabarwa MN, Habomugisha P, Eyamba A, Byamukama E, Nwane P, Arinaitwe $\mathrm{A}$, et al. Community-directed interventions are practical and effective in low-resource communities: experience of ivermectin treatment for onchocerciasis control in Cameroon and Uganda, 2004-2010. Int Health. 2016;8(2):116-23.

14. WHO. African Programme for Onchocerciasis Control: progress report, 20132014. Wkly Epidemiol Rec. 2014:89(49):551-60.

15. Katabarwa M, Richards F. Twice-yearly ivermectin for onchocerciasis: the time is now. Lancet Infect Dis. 2014;14(5):373-4.

16. WHO. Progress towards eliminating onchocerciasis in the WHO Region of the Americas: verification by WHO of elimination of transmission in Colombia. Wkly Epidemiol Rec. 2013;88(36):381-5.

17. WHO. Elimination of onchocerciasis in the WHO Region of the Americas: Ecuador's progress towards verification of elimination. Wkly Epidemiol Rec 2014;89(37):401-5.

18. WHO. Progress toward eliminating onchocerciasis in the WHO Region of the Americas: verification of elimination of transmission in Mexico. Wkly Epidemiol Rec. 2015;90(43):577-81.

19. WHO. Progress towards eliminating onchocerciasis in the WHO Region of the Americas: verification of elimination of transmission in Guatemala. Wkly Epidemiol Rec. 2016;91(43):501-5.

20. WHO. Onchocerciasis: elimination is feasible. Wkly Epidemiol Rec. 2009; 84(37):382-3.

21. Diawara L, Traore MO, Badji A, Bissan Y, Doumbia K, Goita SF, et al. Feasibility of onchocerciasis elimination with ivermectin treatment in endemic foci in Africa: first evidence from studies in Mali and Senegal. PLoS Negl Trop Dis. 2009;3(7):e497.

22. Katabarwa MN, Walsh F, Habomugisha P, Lakwo TL, Agunyo S, Oguttu DW, et al. Transmission of onchocerciasis in wadelai focus of northwestern Uganda has been interrupted and the disease eliminated. J Parasitol Res. 2012;2012:748540

23. WHO. African Programme for Onchocerciasis control: progress report, 20142015. Wkly Epidemiol Rec. 2015;90(49):661-74.

24. Tekle AH, Zoure HG, Noma M, Boussinesq M, Coffeng LE, Stolk WA, Remme $\mathrm{JH}$. Progress towards onchocerciasis elimination in the participating countries of the African Programme for Onchocerciasis control: epidemiological evaluation results. Infect Dis Poverty. 2016;5(1):66.

25. WHO. African Programme for Onchocerciasis Control - report of the sixth meeting of National Task Forces, October 2009. Wkly Epidemio Rec. 2010;85(4):23-8.

26. APOC. Conceptual and operational framework of onchocerciasis elimination with ivermectin treatment; 2010. p. 24.

27. WHO. Guidelines for stopping mass drug administration and verifying elimination of human onchocerciasis: criteria and procedures. In: Guidelines for stopping mass drug administration and verifying elimination of human onchocerciasis: criteria and procedures. Geneva: World Health Organization; 2016.

28. Kamgno J, Bouchite B, Baldet T, Folefack G, Godin C, Boussinesq M. Contribution à l'étude de la répartition des filarioses humaines dans la Province de l'Ouest du Cameroun. Bull Soc Pathol Exot. 1997;90(5):327-30.

29. Katabarwa MN, Eyamba A, Nwane P, Enyong P, Kamgno J, Kuete T, et al. Fifteen years of annual mass treatment of onchocerciasis with ivermectin have not interrupted transmission in the west region of cameroon. J Parasitol Res. 2013;2013:420928.

30. GTNO-Cameroun. Rapport technique annuel 2014. 2015.

31. Albiez EJ. Effects of a single complete nodulectomy on nodule burden and microfilarial density two years later. Trop Med Parasitol. 1985;36(1):17-20.

32. Albiez EJ, Buttner DW, Duke BO. Diagnosis and extirpation of nodules in human onchocerciasis. Trop Med Parasitol. 1988;39(Suppl 4):331-46.

33. Ngoumou P, Walsh JF, Mace JM. A rapid mapping technique for the prevalence and distribution of onchocerciasis: a Cameroon case study. Ann Trop Med Parasitol. 1994;88(5):463-74.
34. Prost A, Prod'hon J. Parasitological diagnosis of onchocerciasis. A critical review of present methods (author's transl). Med Trop (Mars). 1978; 38(5):519-32.

35. BUCREP. Projections démographiques du troisième Recensement Général de la Population et de l'Habitat (3ème RGPH) du Cameroun, vol. 3; 2010. p. 3.

36. Stolk WA, Walker M, Coffeng LE, Basanez MG, de Vlas SJ. Required duration of mass ivermectin treatment for onchocerciasis elimination in Africa: a comparative modelling analysis. Parasit Vectors. 2015;8:552.

37. Kamga GR, Dissak-Delon FN, Nana-Djeunga HC, Biholong BD, MbighaGhogomu S, Souopgui J, et al. Still mesoendemic onchocerciasis in two Cameroonian community-directed treatment with ivermectin projects despite more than 15 years of mass treatment. Parasit Vectors. 2016;9(1):581.

38. Boussinesq M, Demanga-Ngangue, Richard P, Lele D, Cot S, Chippaux JP. Etude clinique et parasitologique de l'onchocercose dans huit villages de la vallée du Mbam. Bull Lias Doc OCEAC. 1992;100:27-31.

39. Walker M, Stolk WA, Dixon MA, Bottomley C, Diawara L, Traore MO, et al. Modelling the elimination of river blindness using long-term epidemiological and programmatic data from Mali and Senegal. Epidemics. 2017;18:4-15.

40. Bottomley C, Isham V, Vivas-Martinez S, Kuesel AC, Attah SK, Opoku NO, et al. Modelling neglected tropical diseases diagnostics: the sensitivity of skin snips for Onchocerca volvulus in near elimination and surveillance settings. Parasit Vectors. 2016;9(1):343.

41. Katabarwa MN, Eyamba A, Nwane P, Enyong P, Yaya S, Baldiagai J, et al. Seventeen years of annual distribution of ivermectin has not interrupted onchocerciasis transmission in north region, Cameroon. Am J Trop Med Hyg. 2011;85(6):1041-9.

42. Baker RH, Guillet P, Seketeli A, Poudiougo P, Boakye D, Wilson MD, Bissan Y. Progress in controlling the reinvasion of windborne vectors into the western area of the Onchocerciasis Control Programme in West Africa. Philos Trans R Soc Lond Ser B Biol Sci. 1990;328(1251):731-47. discussion 747-750

43. Brieger WR, Okeibunor JC, Abiose AO, Ndyomugyenyi R, Kisoka W, Wanji S, et al. Feasibility of measuring compliance to annual ivermectin treatment in the African Programme for Onchocerciasis Control. Tropical Med Int Health. 2007;12(2):260-8.

44. Brieger WR, Okeibunor JC, Abiose AO, Wanji S, Elhassan E, Ndyomugyenyi R, Amazigo UV. Compliance with eight years of annual ivermectin treatment of onchocerciasis in Cameroon and Nigeria. Parasit Vectors. 2011;4:152.

45. Wanji S, Kengne-Ouafo JA, Esum ME, Chounna PW, Adzemye BF, Eyong JE, et al. Relationship between oral declaration on adherence to ivermectin treatment and parasitological indicators of onchocerciasis in an area of persistent transmission despite a decade of mass drug administration in Cameroon. Parasit Vectors. 2015;8(1):667.

\section{Submit your next manuscript to BioMed Central and we will help you at every step:}

- We accept pre-submission inquiries

- Our selector tool helps you to find the most relevant journal

- We provide round the clock customer support

- Convenient online submission

- Thorough peer review

- Inclusion in PubMed and all major indexing services

- Maximum visibility for your research

Submit your manuscript at www.biomedcentral.com/submit
Biomed Central 